\title{
Temperate japonica rice (Oryza sativa L.) breeding: History, present and future challenges
}

\author{
Karla I. Cordero-Lara ${ }^{1 *}$ \\ ${ }^{1}$ Instituto de Investigaciones Agropecuarias, INIA Quilamapu, Av. Vicente Méndez 515, Chillán, Chile. \\ *Corresponding author (kcordero@inia.cl).
}

Received: 18 December 2019; Accepted: 7 March 2020; doi:10.4067/S0718-58392020000200303

\begin{abstract}
Rice is a staple food mainly cultivated in the tropics, however $\sim 20 \%$ of global production originates from temperate regions. The japonica rice (tropical and temperate), is the unique rice type adapted to the temperate conditions through evolution. Nevertheless, at present, there is limited information regarding to breeding of temperate japonica rice because most of the global research and production has been focused on indica rice, which is the most cultivated type ( $\sim 80 \%$ of global production). However, there are many countries where rice is grown under temperate conditions, such as Japan, Russia, Australia, USA, Chile, South Korea, Uzbekistan, Hungary, among others. More information and collaboration between these countries are required to develop better japonica rice cultivars to meet the current agricultural challenges. Here, the japonica rice breeding history, current status and future challenges are compiled to be available to japonica rice breeders, researchers and growers.
\end{abstract}

Key words: Oryza sativa, plant breeding, rice, temperate japonica.

\section{INTRODUCTION}

Cultivated Asian rice (Oryza sativa L.) is a staple for over half the global population, providing about $20 \%$ of the world's dietary energy needs. Unlike other staple grain crops, the majority of rice production is used for human consumption in the form of whole milled kernels. About $90 \%$ of the world's rice is produced and consumed in Asia and represents the most important food crop for poor and developing countries. Annually, more than 700 million tons of rice is produced worldwide on about 161 million hectares (FAOSTAT, 2015). Rice grows in areas with diverse environments: irrigated, rainfed lowland, deep water, upland, and tidal wetlands (Khush, 1997). Particularly irrigated rice cropping requires more water than other crops, at least 2 to 3 times more than other cereals (Kushwaha et al., 2015). The conventional rice production systems (transplanted rice), requires an average of $2500 \mathrm{~L}$ water to produce $1 \mathrm{~kg}$ of rough rice (Bouman et al., 2007). Currently food production is becoming a big challenge and is even more uncertain in the future. Then an analysis of the current situation in rice breeding and production systems is required. Some of the scenarios and new challenges that rice breeding faces are: growing population (highly dependent on rice as the first source of calories), climate change, narrow genetic diversity and sustainable production, among others. Therefore, areas where rice production still can be expanded are attracting the attention of the world. Some of these areas are the temperate regions where temperate rice grows which represents approximately $20 \%$ of the world rice productive surface.

In this context, plant breeding is taking more relevance, and rice breeders will be responsible for the development of rice cultivars adapted to produce more rice with fewer inputs (Bradshaw, 2017). Rice breeders will take the decision of which genetic resources, germplasm and breeding methods will be used to develop the food for the future. It will be also required to exploit the new breeding techniques (NBTs) and find the financial resources to use molecular tools to enhance the new temperate japonica rice. In this review the analysis of the past, present and future of temperate japonica 
rice breeding is proposed to identify the current situation and the gaps that can be worked out to succeed in coping the increasing demand on this crop.

\section{Rice origin and types}

Since its domestication around 10000 years ago, rice has gone through improvements to keep the pace to human feeding needs (Khuswaha et al., 2015). During domestication, some ecotypes from wild species were selected to increase yield. These selections were moved as the human was migrating to the geographic areas where the wild species used to grow (Vaughan et al., 2003). There are two species of cultivated rice: Oryza sativa, originated from O. rufipogon in Asia, and $O$. glaberrima, originated from $O$. barthii in Africa. The most cultivated species is $O$. sativa, which represents almost all world production. Oryza glaberrima is cultivated only in few areas of Africa and lately has been replaced by higher production $O$. sativa containing in its genome some introgressions from O. glaberrima. On the other hand, from $O$. sativa, were derived the indica and japonica groups, probably derived from independent domestication events (Horie et al., 2000; Breseghello, 2013). The subspecies indica included the varietal group indica and aus, while japonica contains temperate japonica, tropical japonica and aromatic as varietal groups (Huang et al., 2012). Indica type is usually cultivated in tropical areas while japonica are grown in temperate regions.

\section{Temperate japonica rice}

Regarding to population structure of $O$. sativa, five varietal groups have been detected: two in indica (indica and aus) and three in japonica (temperate japonica, tropical japonica and aromatic (Doi et al., 2008; Asano et al., 2011). Japonica rice is one of the most important ecological rice types, japonica types differ significantly from indica types in plant architecture, agronomic and physiological traits such as stress resistance, cold tolerance and seed quality (Guo et al., 2015). Temperate and tropical japonica types are genetically close which is reflected by their narrow genetic diversity compared with indica types. Some researchers propose the hypothesis that temperate japonica derived from tropical japonica because of the larger standardized alleles and higher mutation rates showed by temperate japonica (Garris et al., 2005). The narrower diversity found in temperate japonica respect to tropical japonica varieties could be attributed to more intense selection process during domestication (Izawa et al., 2009). Also, it is believed that its adaptation to temperate zones could be due to the extension of its cultivation to northern Asia, in cooler areas than they used to grow. Temperate japonica rice was progressively adapted to shorter growing seasons, flowering in longer days allowing its cultivation in summer seasons, avoiding winters of these colder areas (Naranjo et al., 2014).

\section{Morphological characteristics of japonica rice}

Differences in adaptation and domestication caused several morphological differences between indica and japonica rice ecotypes. These differences are morphological (plant height, pubescence), agronomical (grain length and wide, threshability) and also physiological (hardiness and starch type) (Lu et al., 2009). Japonica varieties are described by the International Rice Research Institute (IRRI) in its bank knowledge webpage (http://www.knowledgebank.irri.org), as a relatively short plant with narrow dark green leaves and medium height tillers. Grains are short and roundish, with no easy shattering, and the spikelets are awnless to long awned. Grains have a low amylose content, ranging from $0 \%$ to $20 \%$, which makes them moist and sticky when they are cooked. Chang (2003) includes the high density of long hairs in lemma and palea of the grain, hard plant tissues, low temperature of gelatinization and low photoperiod sensitivity. Katayama (1993) describing morphological and taxonomical traits of cultivated rice, stated that japonica rice possesses a short second leaf blade, that it has a small angle formed by the second leaf blade and the stem. Also, it has a mid-intermedium angle formed by the flag leaf with the stem and sprouting. The flag leaf is narrow and short in its shape and has the panicle neck node inside of the leaf sheath. Japonica varieties also have abundant hairs on the glume, many erect tillers and many heavy short panicles a short stem and high grain density. All the traits described above show japonica varieties with potential for higher productivity than indica types

\section{Regions where temperate japonica rice is grown}

It is believed that japonica rice moved from southern to northern China and evolved to the temperate japonica ecotype. Also is believed that moved to the south of Southeast Asia and from there to West Africa and Brazil and became tropical 
ecotype. Japonica rice is currently grown between $53^{\circ} \mathrm{N}$ and $36^{\circ} \mathrm{S}$ latitudes under diverse growing conditions such as irrigated, rainfed lowland, rainfed upland and flood-prone ecosystems (Khush, 1997). Temperate japonica rice accounts for $20 \%$ of rice world production, however, the decrease in its production would cause a major food security problem (Jena et al., 2012). Temperate japonica rice is grown in high latitudes, characterized by lower temperatures, and longer days than tropical areas. The crop is only possible in summer seasons where temperatures are favorable. These conditions, mainly more sunlight hours are favorable for crop growth and the yield that can reach easily over $10 \mathrm{t} \mathrm{ha}^{-1}$ (in some cases doubling the tropical indica type). Temperate japonica rice is currently grown in geographically diverse areas, such as Australia, Chile, northwest China, Egypt, North Korea, Russia, Uruguay, Kazakhstan, Uzbekistan, and some parts of USA. In China the cultivated area of temperate japonica rice is increasing with yield accounting for more than $45 \%$ of national production (Guo et al., 2015). In USA, there are two major regions producing rice: the southern rice belt (Arkansas, Louisiana, Texas, Mississippi and Missouri) and California. The south region is mainly focused on the production of tropical japonica rice while in California predominates medium grain temperate japonica rice (Mackill and Lei, 1997). Temperate japonica rice also is grown in mountain areas with high elevations such as Yunnan and Guizhou provinces in China, Laos, Myanmar and Vietnam (Lu et al., 2009).

\section{Cultivation and management of temperate japonica rice}

Rice growing in temperate regions is particularly managed depending on the country and crop system utilized. In northeast China, where temperate japonica rice faces low temperatures, a short growing season, and low rainfall, production is also limited by water scarcity. Temperate japonica rice grown in this region is considered high quality rice and is usually rotated with wheat. In northern China, just one crop per season is possible due to low temperatures during winter, while in the south part of the country, tropical temperatures allow two or three production cycles per season producing indica rice varieties. The crop management used by Chinese farmers is characterized by a high input of fertilizers and pesticides with a weak extension system (Peng et al., 2009). In Japan temperate japonica rice is produced on plains and basins where irrigation is not a problem.

Most of the rice fields are irrigated and cultivated with high yielding rice varieties $\left(7 \mathrm{tha}^{-1}\right)$ that produce more rice than the internal consumption demand. Some major constraints that temperate japonica rice faces in Japan are wind and flood, low temperatures during the summer season and diseases such as rice blast. In the north area, typhoons produce wind and flooding and there is a high pressure of blast, decreasing productivity due to losses in yield. Damage can be present due to extreme high temperature and rice-ear bugs that can cause an increase in pecky and white immature grains lowering the quality and prices of rice (Kato et al., 2012). In Korea temperate japonica rice varieties with high yield occupies the hundred percent of rice cultivation area. Rice grows in irrigated lowlands mainly transplanted, which can be assisted by machine or by hand (the last one in a minimal percentage $\sim 1.2 \%$ ). The growing season starts mid-April and the crop is finally harvested in mid-October. One of the major constraints that rice cultivation faces in Korea is the low temperatures during spring and autumn that can produces injuries reducing yield. Another constraint is the pest and diseases that are mainly controlled by using cultivars multi-resistant and also with helped by chemical control (Kang and Kim, 2012). In Australia, temperate japonica rice is grown in a small geographic area of the southwestern of New South Wales. Rice is grown in monoculture systems or in rotation with other annual crops, and legumes and pasture for livestock. One of the main constrains in Australian rice production is the presence of a severe drought condition. The average yield varies due to low temperature causing sterility during the reproductive stage (Reinke et al., 2012). In Russia, temperate japonica rice is grown using direct seeding into dry soils. It is grown in heavy and saline soils that are not suitable for any other crop. The rice planting area is located between $44^{\circ}$ (Krasnodar) and $49^{\circ}$ (Kalmykiya Republic and Astrakhan) N latitude. There is a predominance of low temperatures during the growth season and there are only 120 to $140 \mathrm{~d}$ with temperatures higher than $15{ }^{\circ} \mathrm{C}$ that allows the rice cultivation (May to August). Total rice area is 200000 ha and the most important rice production area is Krasnodar ( $80 \%$ Russian rice). Cultivation constrains are low temperatures, rice diseases, and ecological insecurity. The national yield average is $5.0 \mathrm{t} \mathrm{ha}^{-1}$ being higher in Krasnodar $6.3 \mathrm{t} \mathrm{ha}^{-1}$ with $10 \mathrm{t} \mathrm{ha}^{-1}$ for the best farmers (Kharitonov, 2012). In USA temperate japonica rice is cultivated in California in the Sacramento Valley ( $38^{\circ}$ to $40^{\circ} \mathrm{N}$ lat). The main and predominant grain type of rice cultivated is medium, accounting the $14 \%$ of the participation in the total rice production in USA. The temperate environment allows the ideal conditions for high yield rice cultivars which can reach average yields of $8.3 \mathrm{tha}^{-1}$. The typical growing season accounts of warm long days and cool nights with 
low humidity which favors an environment with low pressure of pests and diseases. Stem rot and aggregate sheath spot are the diseases present in Californian rice systems. Rice is sowed under flooded condition mainly using pregerminated seed, broadcasted by airplane over high leveled soils. Main efforts have been focused in breed rice varieties with high seedling vigor and high cold tolerant as well as lodging resistant rice (Tai, 2012). In South America temperate japonica rice is cultivated in Chile, which has been grown since the late 1930s. Rice is cultivated in heavy clay soils that are not suitable for the production of any other crop. The rice cultivated area is located in the valleys of the three central-south regions located between $34^{\circ}$ and $36^{\circ} \mathrm{S}$ lat. These valleys have a Mediterranean climate characterized by hot dry summers and cold rainy winters. Rice is grown mainly under flooded conditions, using pregerminated direct seeding, starting in mid-October to harvest in mid-April. It is fertilized with $\mathrm{N}, \mathrm{P}$, and $\mathrm{K}$ and only chemical control of weeds is done during the growing season, since Chile has no pests or diseases of economic importance. The entire production is for domestic consumption and 50\% is indica type imported from countries such as Argentina, Thailand and Paraguay (Cordero, 2012). The Chilean average yield was $6.5 \mathrm{tha}^{-1}$ of long wide grain rice.

\section{Rice breeding history}

Since human civilization plant breeding has been an important activity to develop productive cultivated plants from their wild ancestors (Shenoy and Sharma, 2012). It is described as a combination of art and science that allows the generation of new superior cultivars. Proportions in which art and science are applied in plant breeding process have changed oriented towards science rather than to art. Plant breeding bases are found in Darwin's theory of evolution and the principle of natural selection established by Gregor Mendel (Moose and Mumm, 2008). In the 1900s with the rediscovery, clarification and application of Mendel's laws of inheritance the foundations of modern plant breeding were established (Miflin, 2000; Kushwaha et al., 2015). There are several plant breeding methods, summarized by Breseghello (2013) in three categories: (i) plant selection based on natural variation (nature or existing traditional varieties); (ii) plant selection originated from directed crosses with recombinant desirable genes (mating); and (iii) plant selection assisted by molecular markers to exploit genomic variation. A fourth category could be added considering the creation of new genetic variation through genetic engineering. Independent of the method used in plant breeding; there is a big challenge to face, improving all traits of interest simultaneously. This becomes incredibly difficult because some traits are negatively correlated due to pleiotropic effects, linkage disequilibrium or population structure. In the transition of the 19th and 20th century, the hybridization in plant breeding took more relevance being used until these days (Breseghello, 2013). During the mid of the 1960s, a big revolution occurred when dwarf genes were introduced to wheat and rice, starting the high yielding varieties era. These varieties came to relief the food crisis due to the increase of world population due to advances in medicine and major rate of survival. In the particular case of rice, a cultivar from Taiwan (Taichung Native 1) conferred the dwarf genes to IRRI lines. IR8 was the miracle variety that reached unbelievable yield never seen before (Khush and Brar, 2001; Khush, 2006). The stability of the high yield varieties was increased through the incorporation of genes for disease and insect resistance during the 20th century. However, once again rice demand around the world is increasing in a dramatic way. In Asia $90 \%$ of rice is produced and consumed in situ for half of the world population. It is estimated that only in this region rice demand will increase in $30 \%-50 \%$ by 2025 . Rice production need to increase using same or less land due to urban competition and with the same o fewer resources such as water, fertilizers, pesticides, etc. (Aggarwal et al., 2007). Now the question that arises is how to breed cultivars conciliating crop improvement with genetic crop alteration (to increase their value), in a sustainable manner to protect the environment.

\section{Temperate japonica rice breeding}

Rice breeding programs have been focused on increasing yields, improving tolerance to stresses (biotic and abiotic) and breeding better quality varieties (Khush, 2005). One of the main constraints that japonica rice breeding faces is the narrowness in the germplasm. And there have been some limitations when indica rice types have been used to increase the diversity of japonica rice. Gene introgression from indica to japonica rice has shown problems of high sterility and poor plant type with some linkage drag in the progenies. However, indica germplasm is still a source of diversity for japonica and both types can benefit from desirable traits from each other (Negrao et al., 2008). Nowadays, Asian countries have been increasing the consumption of japonica rice, particularly in the tropics. This trend is observed despise japonica cultivars have a higher price than local indica rice varieties (Ha et al., 2011). As was stated above a central constraint that 
japonica rice breeding has to face that indica does not, is the stress caused by low temperatures. Low temperature affects more than 15 million hectares of rice in the world mainly in temperate and high elevation regions where japonica rice is grown. Low temperatures cause severe sterility in panicles and cold water limits yield. As the changes in temperatures due to global warming become more frequent, rice growing areas will continue moving to the higher latitudes where cold stress becomes an important challenge (Meng et al., 2013). In these areas rice season is characterized by longer days, greater solar radiation than in tropical regions, greater diurnal maximum temperatures and lower night temperatures. These conditions limit the respiration losses and favor a low pressure for pests and diseases. In different regions, rice breeding programs have a particular set of specific goals but there are some main shared goals described by Jena and Hardy (2012). Among them can be found: cold tolerance at reproductive-stage to increase yield stability and water use efficiency, yield potential to increase profitability in rice farming system, and grain quality (mainly milling quality). Other goals are: shorter growth cycle (to save water), improved tolerance of abiotic stresses (salinity, heat, and drought), seedling vigor (to ensure well establishment under low temperature conditions) and lodging resistance.

\section{Challenges in current and future japonica rice breeding}

Increasing cold tolerance in new rice varieties is one of the fundamental goals and challenges that japonica rice breeding faces. Cold tolerance can be defined as the ability of a rice plant to produce grain in a presence of low temperature stress (Shakiba et al., 2017). Currently, there is an increase in vulnerability to weather and pest disruptions due to the low agro-biodiversity level of commercial varieties and seeds. This vulnerability is especially important as shifting and unpredictable climatic conditions are faced (Tracy, 2014). All these challenges makes imperative to generate more genetic diversity, increase yield potential, and breed better climate adapted varieties (e.g. aerobic rice). Also to use direct dry seeding rice, to reduce water use. All of these, integrating technologies such as quantitative trait loci (QTLs), gene sequencing, marker assisted selection to move forward the development of new technologies that will allow overcoming all of these challenges (Kushwaha et al., 2015).

\section{Growing population}

The population is increasing in a fast rate and the requirement of rice is estimated to be increased in around 200 million tons by 2050. To reach that amount of rice production, new technologies and innovations in rice breeding must be used (Kushwaha et al., 2015). In Asia 90\% of rice is produced and consumed in situ for half of the world population. It is estimated that only in this region rice demand will increase $30 \%-50 \%$ by 2025 . Also, a major concern besides the growing population is its nutrition. Currently, more than 800 million people suffer from hunger and malnutrition and also more than a billion people have a low income that is less than 1 dollar per day (Kropff et al., 2007). To improve access to food, society and governments need to take actions to favor the access of poor people to better nutrition, and avoid health problems associated to malnourishment. One part of the solution is breeding bio-fortified rice varieties that provide critical nutrients to people without access to food diversity. There are some efforts as HarvestPlus initiative which depends on Consultative Group for International Agricultural Research (CGIAR) Research Program on Agriculture for Nutrition and Health. Here, staple crops have been bio-fortified using conventional plant breeding techniques to increase the density of vitamins and minerals, sufficient to impact human health and nutrition (http://www.harvestplus.org).

\section{Changes in weather and environments}

Lately, droughts and floods are more frequent, leaving food shortages and damage in fields of the main staple crops worldwide. This shows how dramatic can be extreme weather conditions and the consequences for food security of those regions. Data collected from the United Nation's Intergovernmental Panel on Climate Change (IPCC) showed that more than 100 million people will be added to the undernourishment as a direct consequence of climate change. During the 21 st century, extreme weather events have happened such as heavy precipitation, heat waves and sea level rise. The consequences of these extreme weather have resulted in floods, drought and increasing of salinity of some regions. Until now, all these extreme weather events have been a short duration, but the uncertainty for the future is increasing. It is unknown if these severe extreme weather events will occur longer and more frequently which will be even worse. All of these changes make the production of food a bigger challenge for the future and even more considering the decrease of rice cultivable land and water. Mba et al. (2012) summarized some of the climate changes and their consequences by 
region. In Central and South Asia is predicted that crop yields will decrease by $30 \%$. More than 28 million hectares in arid and semi-arid regions of South and East Asia will need to increase irrigation. For Australia, the prognosis is that there will be reductions in agricultural production by 2030 due to the increment of drought and fires. For North America is predicted an increase in climate sensitivity and as crop yield are now close to climate thresholds are likely to decrease. For Latin America was predicted that by the 2050 s, $50 \%$ of agricultural lands in drier areas may be affected by desertification and salinization and there will be a generalized reduction in rice yields.

\section{Increasing yield and lowering inputs}

There is a challenge in the future of rice breeding in which more rice has to be produced using less land and fewer inputs (e.g. fertilizers, pesticides, water). Since the introduction of dwarfism genes during the green revolution in the 1960s, there has been progressively yield increasing keeping pace with population growth. Through the 20th century, technological innovations were used to increase yield such as indica $\times$ japonica crosses, introduction of semi-dwarf plant height and photo-insensivity, indica $\times$ indica hybrids, indica $\times$ tropical japonica $\times$ temperate japonica crosses that yielded super rice strains, $O$. sativa $\times O$. glaberrima crosses with participative breeding with farmers in Africa which produced the New Rice for Africa (NERICA), use of thermosensitive genetic male sterility (TGMS) among others (Swaminathan, 2007). Even though in most of the temperate rice growing regions some farmers obtain yields close to the potential $\left(10 \mathrm{tha}^{-1}\right)$, still the average farmers only have around $5 \mathrm{t} \mathrm{ha}^{-1}$. To reduce the gap between the potential and current yields there are some tasks to be implemented in farmer fields such as better agronomic management, with special relevance in the fertilization. Nitrogen excesses in temperate rice favor vegetative biomass and sterility. Therefore, development of better adapted varieties with durable resistance to diseases and tolerance to abiotic stresses is required. Other strategies to increase the rice yield potential are working in ideotype breeding, wide hybridizations and genetic engineering (Khush, 2007). Yield potential need to be increased to keep pace with the growing population in the next decades. To reach $15 \mathrm{t} \mathrm{ha}^{-1}$ in inbred varieties (super hybrid rice already reached those potentials), around $30 \mathrm{tha}^{-1}$ of biomass has to be produced which looks difficult with semi-dwarf varieties harboring $s d-1$ locus. Kushwaha et al. (2015) proposed that increasing biomass of rice varieties could be done improving photosynthetic efficiency along with storage capacity for reserve carbohydrates. To approach this, the exploration of interspecific and subspecific variability is proposed to improve physiological efficiency and total biomass per unit of plant height. Sheehy and Mitchell (2013) proposed that improvement in rice yield can be achieved by improving the canopy photosynthesis, through canopy architecture (with adequate vegetative and productive sink capacity to improve $\mathrm{C}$ capture) and the quantum yield of photosynthesis accompanied by adequate crop management. Another approach to increase yield in rice has been investigated recently, trying to create a $\mathrm{C} 4$ rice plant. There is an effort of several research institutions including IRRI in developing $\mathrm{C} 4$ rice to generate a new green revolution to increase rice yield in the new environmental scenario. The International C4 Rice Consortium is working toward introducing a highercapacity photosynthetic mechanism, the $\mathrm{C} 4$ pathway, into rice to increase yield. The goal is to identify the necessary genes to install $\mathrm{C} 4$ photosynthesis in rice using different approaches, such as genomic and transcriptional sequence comparisons and mutant screening (Caemmerer et al., 2012). C4 rice with enhanced photosynthetic mechanism would use solar radiation better producing more grain yield, reduce water loss and increase $\mathrm{N}$ use efficiency especially in hot and dry environments (Karki et al., 2013).

\section{Narrow germplasm}

Years of intensive agriculture and plant breeding, have narrowed the genetic bases of several crops. One of them is rice in which it was seen in previous sections how only little diversity can be found especially between japonica (temperate and tropical). Also many of the old landraces are not present in much of the rice productive areas because they have been displaced by modern varieties. In rice, traditional landraces account for about $70 \%$ of the total collections available in Genebanks worldwide (Negrao et al., 2008). Some breeders are still reticent to use these types of germplasm because of the linkage drag with undesired traits could happen. Around only $15 \%$ of the diversity has been used in rice breeding and in tropical Asia, $95 \%$ of high yielding varieties have been developed based on a single dwarfing gene $S d 1$. In Bangladesh, $62 \%$ descended from common stock. In Indonesia, $74 \%$ descended from common stock and less than 50\% of rice area under three varieties and in Thailand, 50\% area under only two varieties. Narrow genetic variability of commercial cultivars has been reported for several countries such as Brazil, India, and Japan (Kushwaha et al., 2015). In the case of 
temperate japonica rice areas, Kim and Tai (2013) reported that the modern cultivars used in California can be traced back to only 23 ancestral introductions. Aguirre et al. (2005) studied the diversity among the modern rice cultivars in Chile and reported that they possessed high homogeneity and they might be derived from only from a couple of introductions. In Latin America there are only 14 ancestors that originated the rice genetic base in the region (Cuevas Perez et al., 1992). The extreme shortage of genetic diversity in japonica rice germplasm forces to the rice breeders to increase the number of crosses to avoid the depletion of genetic diversity. Strategies such as wide hybridization (using wild ancestors) and the allele mining by Eco TILLING (Targeting Induced Local Lesions In Genomes) to take advantage of the information collected from alleles of a gene completely characterized in germplasm collections have been used (Negrao et al., 2008).

\section{Current and future perspectives in temperate japonica rice breeding}

To move forward in the improvement of japonica rice breeding, some considerations must be taken. Key factors to succeed are innovation and efficiency to redirect crop improvement strategies for the challenges of the 21st century.

Some considerations are: 1) Development of "intelligent" varieties adapted to changing environmental conditions, starting from wild species, local varieties and underused germplasm to discover advantageous traits. 2) Realignment of plant breeding programs, in which biotechnologists, bioinformatics and molecular researchers work together and use the same aggressive technology in a routine manner. International networking will be crucial to use recent technology which some countries cannot afford to develop. 3) Strengthening the 'crop improvement to seed delivery continuum', the continuum that should have conservation, plant breeding and growers that use the new varieties. The germplasm has to be well characterized to be used for breeding programs as well as a good delivery system of the improved cultivars to growers. 4) Winning partnerships, networks and institutional capacities. Partnership must be created between all the parts that made the breeding possible, public sector, private industries, local knowledge, national agricultural centers, consultative groups, and international research institutes. These networks, as training of the new breeders, will be a key point for the success because as Tracy (2014) stated, plant breeding decisions will determine the future of the world's food supply.

\section{Molecular tools available for modern rice breeding}

Conventional breeding is greatly beneficiated for the use of biotechnological tools, allowing faster and more efficient breeding of complex traits such as biotic and abiotic stresses (Negrao et al, 2008). There is a gap between genomics and its application in rice breeding programs, mainly in public programs that do most of the breeding but have restricted funding. Rice is not only important because is a staple food. Rice has the smallest estimated genome size $(400 \mathrm{Mb})$ among cereals compared to maize (3300 Mb), barley $(5100 \mathrm{Mb})$ and wheat $(16000 \mathrm{Mb})$. For this reason, it was selected as a model plant to be used with larger genomes with high level of conservation (Ashikari and Matsuoka, 2006).

\section{Molecular markers}

Molecular markers are one of the most popular biotechnological tools developed in modern times. They can be classified into groups depending on: (1) if there is prior sequence information, (2) how they are transmitted; biparental, uniparental, nuclear or organellar inheritance, (3) mode of interaction dominant or codominant, and (4) method of analysis such as hybridization-based, polymerase chain reaction (PCR)-based or next-generation technology (Patel et al., 2015). The most popular markers in the early days were restriction fragment length polymorphism (RFLP), random amplified polymorphic DNA (RAPD), amplified fragment length polymorphism (AFLP), and microsatellite or simple sequence repeat (SSR). RFLPs and microsatellites are codominant markers and their map positions are known, while RAPD and AFLP markers are based on random positions, which were mainly dominant markers. Microsatellites are PCR-based markers that have been classified as technically efficient and cost-effective to use (Ni et al., 2002). For a long time, SSRs were the most popular and used molecular markers, but recently with the advances in whole-genome sequencing technologies (which significantly reduces the costs), sequence-based molecular markers such as single nucleotide polymorphisms (SNPs) and, most recently genotyping by sequencing (GBS) are becoming more and more popular (Patel et al., 2015). As SNPs happen in a higher density and higher frequency than other markers, they are particularly useful in distinguishing very close related individuals (Kim and Tai, 2013). Molecular markers are one of the most important tools to study the genetic control of traits of interest. They usually would lead to the identification of the genes that are responsible for the trait and 
provide the basis for the knowledge of the metabolic pathways involved (Breseghello, 2013). In rice, molecular markers have been used with several diverse goals such as identification of accessions, to determine the genetic structure of diversity, to characterize cultivars and to build genetic maps. There are several molecular studies of temperate japonica rice for example the analysis of genetic diversity and cold tolerance using SSRs (Suh et al., 2013). Through this study, were identified three cold-tolerant cultivars as potential germplasm source to broaden the gene pool of japonica rice. Yamamoto et al. (2010) analyzed closely related rice cultivars using genome-wide discovery of SNPs. Through the use of a high-throughput typing array consisting of 1917 SNP sites distributed throughout the genome, 151 representative Japanese cultivars grown during the past 150 years were genotyped. It was found that the ancestral origin of the pedigree haplotypes in $60.9 \%$ of the Koshihikari genome and 18 consensus haplotype blocks are inherited from traditional landraces to the modern improved varieties. It was concluded that modern breeding practices were decreasing the genetic diversity in their japonica gene pools. One of the most powerful uses of molecular markers is the marker assisted selection (MAS) in plant breeding. MAS can be used to survey the presence or absence of important genes in breeding populations and make more efficient the conventional rice breeding. Marker assisted backcross has been used to introgress major genes or QTLs into already adapted germplasm accelerating the development of rice varieties. Also, MAS has been used to pyramid disease or pest resistance genes providing opportunities to develop broad spectrum resistance rice varieties. With the reductions in the cost of DNA markers, genes controlling important agronomic traits could be used with MAS to breed better rice cultivars (Jena and Mackill, 2008).

\section{Quantitative trait loci}

Usually, genetic variation is found in a quantitative phenotypic range rather than in qualitative phenotypes that can be distinguished in discrete categories. Several traits of interest are governed by numerous effects of different genes better known as quantitative trait loci (QTL); which explain some portions of the whole phenotypic variation in a particular trait (Paran and Zamir, 2003). QTL mapping is widely used, combining genotypic data collected using molecular markers and phenotypic data from a population to find QTLs that account for the variation in the interest trait. Until recent years QTL mapping was limited by the tedious process of genotyping using molecular markers. However, with the development of various high throughput technologies, now is just a matter of collecting the phenotypic data (Borevitz and Chory, 2004). The information provided by QTLs can be really helpful to increase heritability of desired complex traits. QTLs are especially useful when the traits desired have low levels of heritability such as grain yield, where QTLs and its associated molecular markers accounts for a big portion of the additive genetic effects than the phenotype by itself. Also QTLs are useful to add or delete alleles that contribute to the breeding value. Therefore is very important to identify correctly and precisely these QTL, their stability through time and environments to have a successful breeding result (Moose and Mumm, 2008). In rice there a vast number of QTLs reported. Yano and Sasaki (1997) give an extended list of different QTLs associated with different traits such as panicle weight, grain weight, seedling vigor, and resistance to blast among others. Hao and Lin (2010) also give a summary of QTLs for agronomic importance traits. In temperate japonica rice, several studies reported the discovery of QTLs associated to cold tolerance at seedling and reproductive stage. Although the genetic mechanisms responsible for low temperature tolerance at booting stage are not well known, some QTLs have been successfully identified. Takeuchi et al. (2001) found a total of eight QTLs controlling cold tolerance. Those with the most significant contributions were associated with general cold tolerance ( $q C T-7)$, and cold tolerance related to culm length ( $q C L-1)$ and heading date ( $q H D-3-2$ and $q H D-6)$, explaining $22.1 \%, 31.1 \%, 15.5 \%$, and $50.5 \%$ of the phenotypic variation, respectively. Kuroki et al. (2007) found a QTL for booting stage cold tolerance on chromosome 8 ( $q C T B 8$ ) through the analysis of $\mathrm{F}_{2}, \mathrm{~F}_{3}$, and $\mathrm{F}_{7}$ populations. This QTL explained 26.6\% of the phenotypic variance. Suh et al. (2010) identified three QTLs located on the short arm of chromosomes 3 and 7 and the long arm of chromosome 9. Xu et al. (2008) found eight QTLs on chromosomes 1, 4, 5, 10 and 11 using near-isogenic lines (NILs) developed from temperate japonica rice although the variance explained by each of these was relatively small, ranging from $0.90 \%$ to $14.86 \%$. Ye et al. (2010) found a major QTL on the short arm of chromosome 10 by selective genotyping using $\mathrm{F}_{2}$ and $\mathrm{BC} 1 \mathrm{~F} 1$ populations from crosses between highly tolerant and susceptible japonica. The QTL (qLTSPKST10.1) was validated and mapped by genotyping the entire $\mathrm{F}_{2}$ (282 progeny) and $\mathrm{BC} 1 \mathrm{~F} 1$ ( 84 progeny) populations. A single QTL for cold tolerance at booting stage, $q L T B 3$, was identified on the long arm of chromosome 3 that contributes to $24.4 \%$ of the phenotypic variance (Shirasawa et al., 2012). Shi et al. (2010) identified a QTL in japonica rice landrace Heikezijing which was responsible for broad-spectrum resistance to rice blast. 


\section{Genome sequence}

The sequencing of rice genome was done by the International Rice Genome Sequencing Project (IRGSP) in 2004 and published in Nature in 2005 (International Rice Genome Sequencing Project, 2005; Datta, 2009). In 2002 drafts of the genome sequence of both subspecies of $O$. sativa, indica and japonica were completed (Goff et al., 2002; Yu et al., 2002). This was a breakpoint in rice molecular research providing the foundation for agricultural scientists to move further on their research (Hao and Lin, 2010). About temperate japonica, the sequencing of the temperate japonica rice cultivar Nipponbare set the reference for useful SNPs identification for rice breeding. Since these discoveries several other technologies related to sequencing have been arose among them such as: Genome Wide Association (GWA), gene rich regions (GRRs), new-generation sequencing (NGS) technologies, Sanger sequencing, genotype by sequencing (GBS), restriction enzyme-phased sequencing comparative analyses (RESCAN) among others (Shenoy and Sharma, 2012; Kim and Tai, 2013). Several studies have been done in rice using next-generation sequencing technologies. One of them was done by Kim and Tai (2013), which employed RESCAN to identify and genotype SNPs in 45 rice cultivars which were representing the breeding history in California. More than 20000 putative SNPs were detected using the Nipponbare reference genome which allowed them to identify pedigree haplotypes. It was possible to easily identify haplotype blocks that distinguish the modern cultivars of California from the ancestral short grain temperate japonica. More recently in 2019, Kim et al. developed japonica backcross lines to improve anaerobic germination (AG) tolerance for direct seeding. The indica type Myanmar landrace KHO was used as the AG tolerant donor and Korean japonica rice cultivar with good eating quality, 'Dongan', was the recurrent parent (RP) to develop backcross populations. Marker assisted selection was used to validate target genes ( $A G 1$ and $A G 2$ ). Major agronomic traits were evaluated and four promising lines were examined by $6 \mathrm{~K}$ SNP chip. No linkage drag was observed in these selected lines; therefore they are good candidates to generate new improved japonica rice varieties with desired AG ability to increase Korean rice cultivation area.

\section{Integration of these technologies in temperate japonica rice breeding of the 21 st century}

Through history, plant breeding has been integrating the latest innovations in biology and genetics to enhance crop improvement. Even though there are several technologies that have been developed recently (e.g. next generation sequencing), still there is a challenge in the integration of these tools with plant breeding. This is critical because most of rice breeding programs depend on the public sector where financial resources are limited and scarce. Moose and Mumm (2008) stated that the technologies integration will require that the new rice breeders have to be familiar and have knowledge of genomics, function of genes, statistical approaches (to estimate genetic effects), background in plant biology and experience in laboratory methods as well as field based breeding practices and ability to manage large datasets with diverse type of data. Because of the broadness of each discipline mentioned above, big efforts are required in the implementation of research and education programs that promote the simultaneous function of molecular and conventional breeding.

\section{Complex traits in temperate japonica rice facing future challenges}

There is a huge need to improve yields and performance in general of rice to reach the amount of grain necessary to feed the growing population. New rice varieties have to be more productive in changing environments and with lower amounts of inputs. Traits that are difficult to breed are yields, short growth cycle (early flowering), abiotic stress tolerance (cold, heat, and drought tolerance), all of them controlled by several genes. One of the most important traits for temperate rice regions is cold tolerance, which is crucial for plants to be able to grow and produce in temperate conditions. Improvements in cold tolerance will lead to a type of rice variety that will perform better under water restricted conditions. This because in most temperate rice countries, high water levels are used as thermic protection to avoid low temperatures when plants are more sensitive to cold damage (e.g. panicle initiation). Then, if rice breeders are able to increase cold tolerance, water can also be reduced. Most of the countries were temperate japonica rice is currently cultivated (e.g. USA [California], Korea, Japan, Chile) have experienced shortages of water by prolonged drought as well as competence with other crops and uses. It is expected that in the future less water will be available for rice cultivation. One of the strategies that can be used to save water in the rice paddy fields is the direct drill seeding, in which dry seeds are sown in dry soils and irrigate twice or three times while seeds are germinating and afterwards crop is established under permanent flooding. This system reduces considerable amounts of water and it has been recently introduced in temperate regions. However, most of the 
temperate japonica rice varieties have been breed under flooding conditions and better varieties (higher cold tolerance and more water use efficient) are required to ensure a well establishment under water restricted conditions. These new varieties will also require competing against weeds to maintain a good plant stand and ensure high yield.

\section{CONCLUSIONS}

To continue producing rice in temperate regions, breeders must combine genetic knowledge and the technological advances to discover the right and desired genes to make new better rice varieties. At the same time, development of these varieties needs to be faster, more efficient and more effective to meet all the challenges analyzed before. These rice varieties will be the key to improve rice production worldwide, cultivation conditions for farmers and, the most important, to feed the population in the future.

\section{REFERENCES}

Aggarwal, P.K., Ladha, J.K., Singh, R.K., Devakumar, C., Hardy, B. (eds.) 2007. Science, technology, and trade for peace and prosperity. Proceedings of the 26th International Rice Research Conference, New Delhi, India. 9-12 October 2006. International Rice Research Institute, Los Baños (Philippines), and Indian Council of Agricultural Research, and National Academy of Agricultural Sciences, New Delhi, India. Macmillan, New Delhi, India.

Aguirre, C., Alvarado, R., and Hinrichsen, P. 2005. Identification of Chilean rice cultivars and breeding lines by means of amplified fragment length polymorphism (AFLP). Agricultura Técnica (Chile) 65(4):356-369

Asano, K., Yamasaki, M., Takuno, S., Miura, K., Katagiri, S., Ito, T., et al. 2011. Artificial selection for a green revolution gene during japonica rice domestication. Proceedings of the National Academy of Sciences of the United States of America 108(27):11034-11039.

Ashikari, M., and Matsuoka, M. 2006. Identification, isolation and pyramiding of quantitative trait loci for rice breeding. Trends in Plant Science 11(7):344-350.

Borevitz, J.O., and Chory, J. 2004. Genomics tools for QTL analysis and gene discovery. Current Opinion in Plant Biology 7:132-136.

Bouman, B.A.M., Lampayan, R.M., and Tuong, T.P. 2007. Water management in irrigated rice: Coping with water scarcity. International Rice Research Institute, Los Baños, Philippines.

Bradshaw, J.E. 2017. Plant breeding: Past, present and future. Euphytica 213:60. https://doi.org/10.1007/s10681-016-1815-y.

Breseghello, F. 2013. Traditional and modern plant breeding methods with examples in rice (Oryza sativa L.) Journal of Agriculture Food Chemistry 61:8277-8286.

Caemmerer, S., Quick, W.P., and Furbank, R.T. 2012. The development of C4 rice: Current progress and future challenges. Science 336:1671-1672.

Chang, T. 2003. Origin, domestication, and diversification. In Smith C.W., and Dilday, R.H. (eds.) Rice: Origin, history, technology, and production. Wiley, Hoboken, New Jersey, USA.

Cordero, K. 2012. Temperate rice in Chile. In Temperate rice in Japan. In Advances in temperate rice research. International Rice Research Institute (IRRI), Los Baños, Philippines.

Cuevas Perez, F.E., Guimaraes, E.P., Berrio, L.E., and Gonzales, D.I. 1992. Genetic base of the irrigated rice in Latin America and the Caribbean. Crop Science 32(4):1054-1059.

Datta, S.K. (ed.) 2009. Rice improvement in the genomics era. CRC Press, Boca Raton, Florida, USA.

Doi, K., Yasui, H., and Yoshimura, A. 2008. Genetic variation in rice. Current Opinion in Plant Biology 11:144-148.

FAOSTAT. 2015. FAOSTAT database. Food and Agriculture Organization (FAO), Rome, Italy.

Garris, A.J., Tai, T.H., Coburn, J., Kresovich, S., and McCouch, S. 2005. Genetic structure and diversity in Oryza sativa L. Genetics 169:1631-1638.

Goff, S.A., Ricke, D., Lan, T.H., Presting, G., Wang, R.L., Dunn, M., et al. 2002. A draft sequence of the rice genome (Oryza sativa L. ssp. japonica). Science 296:92-100.

Guo, L., Guo, W., Zhao, H., Wang, J., Liu, H., Sun, J., et al. 2015. Association mapping and resistant alleles analysis for japonica rice blast resistance. Plant Breeding 134:646-652.

Ha, W.G., Torollo, G.V., Kang, K.H., Lapiz, M., and Padolina, T.F. 2011. Breeding temperate japonica rice MS11 for the tropics. Philippine Journal of Crop Science (Philippines) 36(1):111-131.

Hao, W., and Lin, H.X. 2010. Toward understanding genetic mechanisms of complex traits in rice. Journal Genetics and Genomics 37:653-666.

Horie, T., Baker, J.T., Nakagawa, H., Matsui, T., and Kim, H.Y. 2000. Crop ecosystem responses to climatic change: Rice. In Reddy, K.R., and Hodges, H.F. (eds.) Climate change and global crop productivity. CAB International, Wallingford, UK. 
Huang, X., Kurata, N., Wei, X., Wang, Z.X., Wang, A., Zhao, Q., et al. 2012. A map of rice genome variation reveals the origin of cultivated rice. Nature 490:497-501.

International Rice Genome Sequencing Project (IRGSP). 2005. The map-based sequence of the rice genome. Nature 436:793-800.

Izawa, T., Konishi, S., Shomura, A., and Yano, M. 2009. DNA changes tell us about rice domestication. Current Opinion in Plant Biology 12:185-192.

Jena, K.K., and Hardy, B. 2012. Advances in temperate rice research. International Rice Research Institute (IRRI), Los Baños, Philippines.

Jena, K.K., and Mackill, D.J. 2008. Molecular markers and their use in marker-assisted selection in rice Crop Science 48:1266-1276.

Kang, K.H., and Kim, Y.G. 2012. Temperate rice in Korea. p. 43-48. In Jena, K.K., and Hardy, B. (eds.) In Advances in temperate rice research. International Rice Research Institute (IRRI), Los Baños, Philippines.

Karki, S., Rizal, G., and Quick, W.P. 2013. Improvement of photosynthesis in rice (Oryza sativa L.) by inserting the C4 pathway. Rice 6:28.

Katayama, T.C. 1993. Indica, japonica and javanica. In Matsuo, T., and Hoshikawa, K. (ed.) Science of the rice plant. Volume 1. Morphology. CAB International, Wallingford, UK.

Kato, H., Matsushita, K., and Yano, M. 2012. Temperate rice in Japan. In Advances in temperate rice research. International Rice Research Institute (IRRI), Los Baños, Philippines.

Kharitonov, E. 2012. Problems of growing rice in Russia and ways to solve them. In Advances in temperate rice research. International Rice Research Institute (IRRI), Los Baños, Philippines.

Khush, G.S. 1997. Origin, dispersal, cultivation and variation of rice. Plant Molecular Biology 35:25-34.

Khush, G. 2005. What it will take to feed 5.0 billion rice consumers in 2030. Plant Molecular Biology 59:1-6.

Khush, G.S. 2006. Rice breeding: Accomplishments and challenges for future food security. Ritsumeikan International Affairs 4:25-36.

Khush, G.S. 2007. Rice breeding for the 21st Century. In Science, technology, and trade for peace and prosperity. Proceedings of the 26th International Rice Research Conference, New Delhi. 9-12 October 2006. International Rice Research Institute (IRRI), Los Baños, Philippines, and Indian Council of Agricultural Research, and National Academy of Agricultural Sciences, New Delhi, India. Macmillan, New Delhi, India.

Khush, G.S., and Brar, D.S. 2001. Rice genetics from Mendel to functional genomics. p. 3-25. In Khush, G.S., Brar, D.S., and Hardy, B. (eds.) Rice Genetics IV. Proceedings 4th International Rice Genetics Symposium, Los Baños. 22-27 October 2000. World Scientific Publishing, Singapore.

Kim, S.I., and Tai, T.H. 2013. Identification of SNPs in closely related temperate japonica rice cultivars using restriction enzymephased sequencing. PLOS ONE 8(3):e60176.

Kim, S.M., Kim, C.S., Jeong, J.U., Reinke, R.F., and Jeong, J.M. 2019. Marker-assisted breeding for improvement of anaerobic germination in japonica rice (Oryza sativa). Plant Breeding 138(6):810-819. doi:10.1111/pbr.12719.

Kropff, M.J., Bindraban, P.S., and Slingerland, M.A. 2007. Competing claims for natural resources and the need for system transitions in rice cultivation. In Science, technology, and trade for peace and prosperity. Proceedings of the 26th International Rice Research Conference, New Delhi. 9-12 October 2006. International Rice Research Institute (IRRI), Los Baños, Philippines, Indian Council of Agricultural Research, and National Academy of Agricultural Sciences, New Delhi, India. Macmillan, New Delhi, India.

Kuroki, M., Saito, K., Matsuba, S., Yokogami, N., Shimizu, H., Ando, I., et al. 2007. A quantitative trait locus for cold tolerance at the booting stage on rice chromosome 8. Theoretical and Applied Genetics 115:593-600.

Kushwaha, U.K.S., Khatiwada, S.P., Upreti, H.K., Shah, U.S., Thapa, D.B., Dhami, N.B., et al. 2015. Modification of rice breeding technology in 21st Century. International Journal of Bioinformatics and Biomedical Engineering 1(2):77-84.

Lu, B.R., Cai, X., and Jin, X. 2009. Efficient indica and japonica rice identification based on the InDel molecular method: Its implication in rice breeding and evolutionary research. Progress in Natural Science 19:1241-1252.

Mackill D., and Lei, X. 1997. Genetic variation for traits related to temperate adaptation of rice cultivars. Crop Science 37:1340-1346.

Mba, C., Guimaraes, E.P., and Ghosh, K. 2012. Re-orienting crop improvement for the changing climatic conditions of the $21 \mathrm{st}$ century. Agriculture and Food Security 1:7.

Meng, L., Lin, X., Wang, J., Chen, K., Cui, Y., Xu, J., et al. 2013. Simultaneous improvement in cold tolerance and yield of temperate japonica rice (Oryza sativa L.) by introgression breeding. Plant Breeding 132:604-612.

Miflin, B. 2000. Crop improvement in the 21 st century. Journal of Experimental Botany 51(342):1-8.

Moose, S.P., and Mumm, R.H. 2008. Molecular plant breeding as the foundation for 21st century crop improvement. Plant Physiology 147:969-977.

Naranjo, L., Talón, M., and Domingo, C. 2014. Diversity of floral regulatory genes of japonica rice cultivated at northern latitudes. BMC Genomics 15:101. 
Negrao, S., Oliveira, M.M., Jena, K.K., and Mackill, D. 2008. Integration of genomic tools to assist breeding in the japonica subspecies of rice. Molecular Breeding 22:159-168.

Ni, J., Colowit, P.M., and Mackill, D.J. 2002. Evaluation of genetic diversity in rice subspecies using microsatellite markers. Crop Science 42:601-607.

Paran, I., and Zamir, D. 2003. Quantitative traits in plants: beyond the QTL. Trends in Genetics 19:303-306.

Patel, D.A., Zander, M., Dalton-Morgan, J., and Batley, J. 2015. Advances in plant genotyping: Where the future will take us. In Batley, J. (ed.) Plant genotyping: Methods and protocols. Methods in Molecular Biology (Book 1245). Humana Press, Totowa, New Jersey, USA.

Peng, S., Tang, Q., and Zou, Y. 2009. Current status and challenges of rice production in China. Plant Production Science 12:1-6.

Reinke, R., Beecher, G., Dunn, B., and Snell, P. 2012. Temperate rice in Australia. In Advances in temperate rice research. International Rice Research Institute (IRRI), Los Baños, Philippines.

Shakiba, E., Edwards, J.D., Jodari, F., Duke, S.E., Baldo, A.M., Korniliev, P., et al. 2017. Genetic architecture of cold tolerance in rice (Oryza sativa) determined through high resolution genome-wide analysis. PLOS ONE 12(3):e0172133. https://doi.org/10.1371/journal.pone.0172133.

Sheehy, J.E., and Mitchell, P.L. 2013. Designing rice for the 21st century: the three laws of maximum yield. Discussion Paper Series 48. 19 p. International Rice Research Institute (IRRI), Los Baños, Philippines.

Shenoy, V., and Sharma, N.P. 2012. New facets of 21st Century plant breeding. Journal of Rice Research 5(1 \& 2):1-17.

Shi, X., Wang, J., Bao, Y., Li, P., Xie, L., Huang, J., et al. 2010. Identification of the quantitative trait loci in japonica rice landrace Heikezijing responsible for broad-spectrum resistance to rice blast. Phytopathology 100:822-829.

Shirasawa, S., Endo T., Nakagomi, K., Yamaguchi, M., and Nishio, T. 2012. Delimitation of a QTL region controlling cold tolerance at booting stage of a cultivar, 'Lijiangxintuanheigu', in rice, Oryza sativa L. Theoretical and Applied Genetics 124:937-946.

Suh, J.P., Cho, Y.C., Lee, J.H., Lee, S.B., Jung, J.Y., Choi, I.S., et al. 2013. SSR analysis of genetic diversity and cold tolerance in temperate rice germplasm. Plant Breeding and Biotechnology 7(2):103-110.

Suh, J.P., Jeung, J.U., Lee, J.I., Choi, Y.H., Yea, J.D., Virk, P.S., et al. 2010. Identification and analysis of QTLs controlling cold tolerance at the reproductive stage and validation of effective QTLs in cold tolerant genotypes of rice (Oryza sativa L.) Theoretical and Applied Genetics 120(5):985-995.

Swaminathan, M.S. 2007. Science and shaping the future of rice. In Science, technology, and trade for peace and prosperity. Proceedings of the 26th International Rice Research Conference, New Delhi. 9-12 October 2006. International Rice Research Institute (IRRI), Los Baños, Philippines, Indian Council of Agricultural Research, and National Academy of Agricultural Sciences, New Delhi, India. Macmillan, New Delhi, India.

Tai, T.H. 2012. Temperate rice in the U.S. In Advances in temperate rice research. International Rice Research Institute (IRRI), Los Baños, Philippines.

Takeuchi, Y., Hayasaka, H., Chiba, B., Tanaka, I., Shimano, T., Yamagishi, M., et al. 2001. Mapping quantitative trait loci controlling cool-temperature tolerance at booting stage in temperate japonica rice. Breeding Science 51:191-197.

Tracy, W.F. 2014. Food security and the role of public cultivar development. p. 39-51. In Tracy, B., and Sligh, M. (eds.) Proceedings of the 2014 Summit on Seeds and Breeds for 21st Century Agriculture, Washington, DC. 5-7 March. Rural Advancement Foundation International (RAFI), Pittsboro, North Carolina, USA.

Vaughan, D.A., Morishimay, H., and Kadowaki, K. 2003. Diversity in the Oryza genus. Current Opinion in Plant Biology 6:139-146.

Xu, L.M., Zhou, L., Zeng, Y.W., Wang, F.M., Zhang, H.L., Shen, S.Q., et al. 2008. Identification and mapping of quantitative trait loci for cold tolerance at the booting stage in a japonica rice near isogenic line. Plant Science 174:340-347.

Yamamoto, T., Nagasaki, H., Yonemaru, J., Ebana, K., Nakajima, M., Shibaya, T., et al. 2010. Fine definition of the pedigree haplotypes of closely related rice varieties by means of genome-wide discovery of single nucleotide polymorphisms. BMC Genomics 11:267.

Yano, M., and Sasaki, T. 1997. Genetic and molecular dissection of quantitative traits in rice. Plant Molecular Biology 35:145-153.

Ye, C., Fukai, S., Godwin, I.D., Koh, H., Reinke, R., Zhou, Y., et al. 2010. A QTL controlling low temperature induced spikelet sterility at booting stage in rice. Euphytica 176:291-301.

Yu, J., Hu, S., Wang, J., Wong, G.K., Li, S. Liu, B., et al. 2002. A draft sequence of the rice genome (Oryza sativa L. ssp. indica). Science 296:79-92. 